\title{
Prognostic impact of programmed cell death ligand 1 expression on long-term oncologic outcomes in colorectal cancer
}

\author{
SUNG UK BAE ${ }^{1,2}$, WOON KYUNG JEONG ${ }^{1}$, SEONG KYU BAEK ${ }^{1}$, NAM KYU KIM ${ }^{2}$ and ILSEON HWANG ${ }^{3}$ \\ ${ }^{1}$ Department of Surgery, Keimyung University School of Medicine, Dongsan Medical Center, Daegu 41931; ${ }^{2}$ Division of \\ Colorectal Surgery, Department of Surgery, Colorectal Cancer Clinic, Severance Hospital, Yonsei University \\ College of Medicine, Seoul 03722; ${ }^{3}$ Department of Pathology, Keimyung University School of Medicine, \\ Dongsan Medical Center, Daegu 41931, Republic of Korea
}

Received March 1, 2018; Accepted July 25, 2018

DOI: $10.3892 / \mathrm{ol} .2018 .9264$

\begin{abstract}
The present study evaluated the association between programmed cell death ligand-1 (PD-L1) expression and long-term oncologic outcomes in colorectal cancer (CRC). PD-L1 expression was evaluated using immunohistochemistry in 175 patients who underwent surgical resection for CRC between September 1999 and August 2004. Patients were grouped according to PD-L1 expression, with 82 (46.9\%) and $93(53.1 \%)$ in the low and high PD-L1 expression groups, respectively. The overall survival (OS) and disease-free survival (DFS) rates were significantly better in the high expression group compared with in the low expression group (OS: 48.2 vs. $32.9 \%, \mathrm{P}=0.047$; $\mathrm{DFS}: 43.3$ vs. $32.9 \%, \mathrm{P}=0.021$ ). According to the Tumor-Node-Metastasis stage subgroups, the OS rates in the low and high expression groups, respectively, were 66.7 and $60.0 \%$ in stage $\mathrm{I}(\mathrm{P}=0.715), 51.8$ and $46.7 \%$ in stage II $(\mathrm{P}=0.789), 19.6$ and $51.1 \%$ in stage III $(\mathrm{P}=0.011)$ and 9.1 and $0 \%$ in stage IV $(\mathrm{P}=0.005)$. The DFS rates in the low and high expression groups, respectively, were 66.7 and $60.0 \%$ in stage I $(\mathrm{P}=0.715), 51.8$ and $46.7 \%$ in stage II $(\mathrm{P}=0.857)$, 19.6 and $38.3 \%$ in stage III $(\mathrm{P}=0.006)$ and 9.1 and $0 \%$ in stage IV $(\mathrm{P}=0.700)$. The systemic recurrence rate was significantly higher in the low expression group compared with in the high expression group (42.7 vs. $12.9 \%$, respectively, $\mathrm{P}=0.030$ ). Low PD-L1 expression was significantly associated with tumor relapse and poor prognosis in stage III CRC.
\end{abstract}

\section{Introduction}

Colorectal cancer (CRC) is one of the most common types of cancer in Korea and other developed countries $(1,2)$. The

Correspondence to: Dr Ilseon Hwang, Department of Pathology, Keimyung University School of Medicine, Dongsan Medical Center 194 Dongsan-Dong, Jung-Gu, Daegu 41931, Republic of Korea E-mail: ilseon@dsmc.or.kr

Key words: colorectal neoplasms, programmed cell death 1 receptor, prognosis, survival analysis carcinogenesis of CRC is driven by genetic and epigenetic changes in tumor cells and is also influenced by tumor-host interactions (3-5). Previous studies have reported the potential association of molecular markers such as BRAF, KRAS, and MMR with prognosis in patients with CRC $(6,7)$. Identification of the predictors of poor prognosis and disease recurrence is important for the successful treatment of these patients and for the discovery of new therapeutic strategies.

Analysis of host immunity against human malignancy is increasingly important in cancer research and treatment $(8,9)$. Immune checkpoints represent a major defense system of the tumor against antitumor immunity in the host and play an important role in suppressing the T-cell-mediated immune response in the tumor microenvironment $(9,10)$. Programmed cell death ligand-1 (PD-L1) expression in tumor cells suppresses the cytotoxic activity of CD8-positive T-cells (11-13). Up-regulation of PD-L1 has been reported in malignancies including lung cancer, esophageal cancer, renal cell carcinoma, ovarian cancer, CRC, and breast cancer and may play a central role in tumor-immune system interactions (14-19).

PD-L1 expression in tumor cells may be linked to a weakened host immune response, resulting in immune escape and an adverse prognosis in several malignancies (20-22). However, the prognostic role of PD-L1 expression in CRC is less clear, with some studies reporting conflicting results as to whether PD-L1 expression indicates a better or worse prognosis. The prognostic evaluation in these studies has been limited because they included patients at various disease stages and different study populations (23-27). The aim of this study was to evaluate the correlation between PD-L1 expression and long-term oncologic outcomes in CRC.

\section{Materials and methods}

Patients. Formalin-fixed paraffin-embedded block specimens from surgical resection of the primary tumor were obtained from 175 patients with CRC who underwent curative surgery and adjuvant chemotherapy at our institution between September 1999 and August 2004. Baseline clinicopathological characteristics and clinical outcome data were retrospectively collected from the Colorectal Cancer Database of the Department of Colorectal Cancer Surgery 

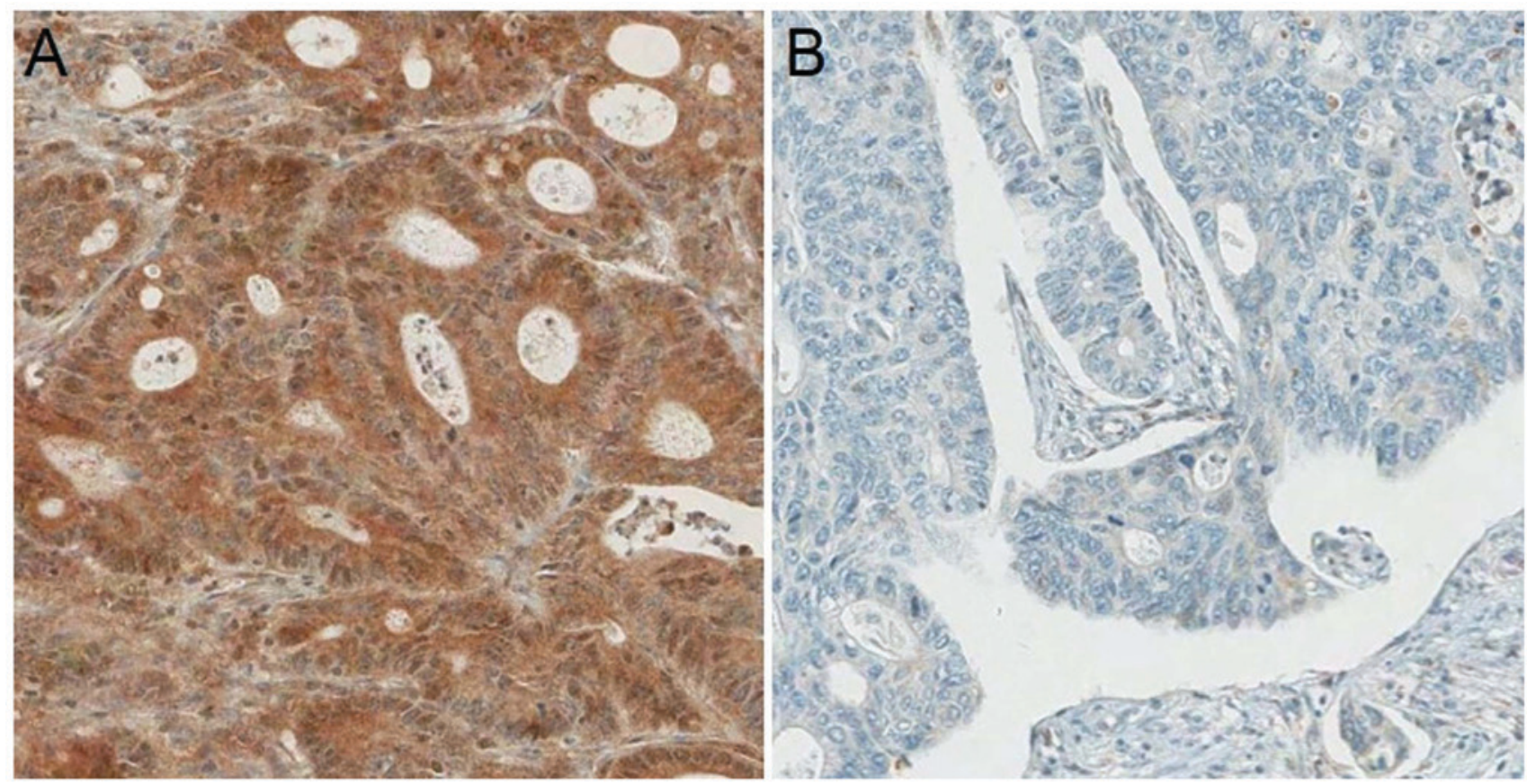

Figure 1. (A) High (52.8\%) and (B) low (47.2\%) PD-L1 expression.

and the Pathological Diagnosis Database in the Department of Pathology. The study physicians reviewed all medical records related to $\mathrm{CRC}$, extracted clinical information including the American Joint Committee on Cancer tumor, node, metastases (TNM) classification, the numbers of positive and negative lymph nodes harvested and tumor location, and determined cause of death in deceased individuals.

Production of tissue microarray block. Formalin-fixed, paraffin-embedded tissue samples were produced for tissue microarray (TMA). Representative areas of each tumor were marked on each hematoxylin and eosin-stained slide and the corresponding area of the tissue blocks was sampled. The designated area of each donor block was collected using a tissue cylinder punch ( $3 \mathrm{~mm}$ diameter), and the samples were transferred to a recipient block.

Immunohistochemistry. Sections (4 $\mu \mathrm{m}$ thickness) from the TMAs were cut in $10 \%$ formalin buffer, embedded in paraffin, mounted onto Superfrost Plus glass slides (VWR Scientific, West Chester, PA, USA), and incubated at $60^{\circ} \mathrm{C}$ for $15 \mathrm{~min}$. The slides were deparaffinized in xylene, rehydrated in graded alcohol solutions, and washed in tap water. Endogenous peroxidase activity was blocked by the addition of $3 \% \mathrm{H}_{2} \mathrm{O}_{2}$. The slides were placed in a steam cooker filled with $10 \mathrm{mM}$ sodium citrate buffer ( $\mathrm{pH}$ 6.0) for antigen retrieval after treatment with a blocking agent (DAKO, Carpinteria, CA, USA) for 10 min to block nonspecific protein binding. Immunohistochemistry for antigen (PD-L1) was performed using an autostainer (LV360-2D; LabVision Co., Fremont, CA, USA). Reagents and the secondary antibody from the commercial LP Kit (TL-125-HD, LabVision Co.) were used as provided by the manufacturer. The primary antibody was a rabbit polyclonal antibody against PD-L1 (1:400, Anti-PD-L1; AnaSpec, Fremont, CA, USA). Immunopositivity was evaluated by determining the proportions of positive cells (low, $\leq 50 \%$; and high, $>50 \%$ ).

Evaluation parameters. The sixth edition of the American Joint Committee on Cancer (AJCC) classification system was used to determine the pathological tumor depth (pT), the number of metastasized lymph nodes $(\mathrm{pN})$, and cancer stage. A postoperative clinical examination, measurement of serum carcinoembryonic antigen CEA levels, chest radiography every 3 months, and chest/abdominal computed tomography (CT) every 6 months were performed during each follow-up examination over a period of 3 years. After 3 years, the follow-up interval was changed to 6 months. Recurrence was defined as the presence of radiologically confirmed or histologically proven tumor and the location of recurrence was defined as the first site of recurrence after complete resection. Local recurrence was defined as any tumor recurrence in the surgical field; local recurrence with synchronous systemic recurrence was included systemic recurrence. The overall survival (OS) time was defined as the time from the date of surgery to the date of the latest follow-up visit or the date of death due to any cause, while the disease-free survival (DFS) time was defined as the time from surgery to any type of recurrence.

Statistical analyses. Data were expressed as medians with ranges. Differences in clinicopathological features between low and high-intensity PD-L1-positive CRCs were analyzed by Chi-square or Fisher's exact tests for categorical variables and Student's t-test for continuous variables. Survivals rate were determined using the Kaplan-Meier method and log-rank tests were used to compare survival rates among subgroups. Log-rank tests were also used for univariate analysis and independent prognostic factors were identified by multivariate analysis using the Cox proportional hazards model to calculate hazard ratios. All statistical tests were performed using IBM 
Table I. Characteristics of patients with CRC according to programmed death-ligand 1 status.

\begin{tabular}{|c|c|c|c|}
\hline Characteristics & Low expression $(\mathrm{N}=82)$ & High expression $(\mathrm{N}=93)$ & P-value \\
\hline Age (years), median (range) & $67(32-86)$ & $70(39-100)$ & 0.310 \\
\hline Sex, n $(\%)$ & & & 0.711 \\
\hline Male & $48(58.5)$ & $57(61.3)$ & \\
\hline Female & $34(41.5)$ & $36(38.7)$ & \\
\hline Preoperative CEA (ng/ml), median (range) & $2.82(0.3-416.8)$ & $3.50(0.1-332.8)$ & 0.762 \\
\hline Tumor location, n (\%) & & & 0.073 \\
\hline Right side & $10(12.2)$ & $21(22.6)$ & \\
\hline Left side & $72(87.8)$ & $72(77.4)$ & \\
\hline Tumor stage, n (\%) & & & 0.325 \\
\hline $\mathrm{T} 1$ & $0(0)$ & $2(2.2)$ & \\
\hline $\mathrm{T} 2$ & $11(13.4)$ & $18(19.4)$ & \\
\hline T3 & $64(78.0)$ & $68(73.1)$ & \\
\hline $\mathrm{T} 4$ & $7(8.5)$ & $5(5.4)$ & \\
\hline Nodal stage, $\mathrm{n}(\%)$ & & & 0.109 \\
\hline N0 & $36(43.9)$ & $46(49.5)$ & \\
\hline N1 & $20(24.4)$ & $30(32.3)$ & \\
\hline N2 & $26(31.7)$ & $17(18.3)$ & \\
\hline TNM stage, $\mathrm{n}(\%)$ & & & 0.100 \\
\hline Stage I & $6(7.3)$ & $15(16.1)$ & \\
\hline Stage II & $30(36.6)$ & $30(32.3)$ & \\
\hline Stage III & $35(42.7)$ & $43(46.2)$ & \\
\hline Stage IV & $11(13.4)$ & $5(5.4)$ & \\
\hline Histology, n (\%) & & & 0.184 \\
\hline Well-differentiated & $4(4.9)$ & $4(4.3)$ & \\
\hline Moderately differentiated & $67(81.3)$ & $84(90.3)$ & \\
\hline Poorly differentiated & $8(9.8)$ & $2(2.2)$ & \\
\hline Mucinous & $3(3.7)$ & $3(3.2)$ & \\
\hline Lymphovascular invasion, $\mathrm{n}(\%)$ & $61(74.4)$ & $64(68.8)$ & 0.415 \\
\hline Perinodal extension, n (\%) & $15(18.3)$ & $10(10.8)$ & 0.155 \\
\hline Recurrence pattern, n (\%) & & & 0.199 \\
\hline Local recurrence & $7(18.4)$ & $7(38.9)$ & \\
\hline Systemic recurrence & $28(73.7)$ & $9(50.0)$ & \\
\hline Local and systemic recurrence & $3(7.9)$ & $2(8.9)$ & \\
\hline
\end{tabular}

CRC, colorectal cancer; CEA, carcinoembryonic antigen; TNM, tumor-node-metastasis.

SPSS Statistics for Windows, v.21.0 (IBM Corp., Armonk, NY, USA). $\mathrm{P}<0.05$ was considered to indicate a statistically significant difference.

Ethical statement. The study was approved by the Institutional Review Board of Keimyung University and Donsan Medical Center (IRB no. 2017-11-037) and performed in accordance with the principles of the Declaration of Helsinki. The informed consent was waived.

\section{Results}

Patient and tumor characteristics. PD-L1 expression was categorized as low in $82(46.9 \%)$ patients and high in $93(53.1 \%)$ patients (Fig. 1). The patient and tumor characteristics of the study cohort stratified by PD-L1 status are shown in Table I. The demographic characteristics were similar between the two cohorts for age, sex, preoperative carcinoembryonic antigen level, tumor stage, nodal stage, TNM stage, histology, lymphovascular invasion, and perinodal extension. There was a trend in tumors to be located in the right-sided colon, although without statistical significance, in the high PD-L1 expression group compared to the low PD-L1 expression group (22.6 vs. $12.2 \%, \mathrm{P}=0.073$ ).

Oncologic outcomes and recurrence pattern according to PD-L1 expression. During the median follow-up period of 88 months (range 1-196 months), the total numbers of deaths 

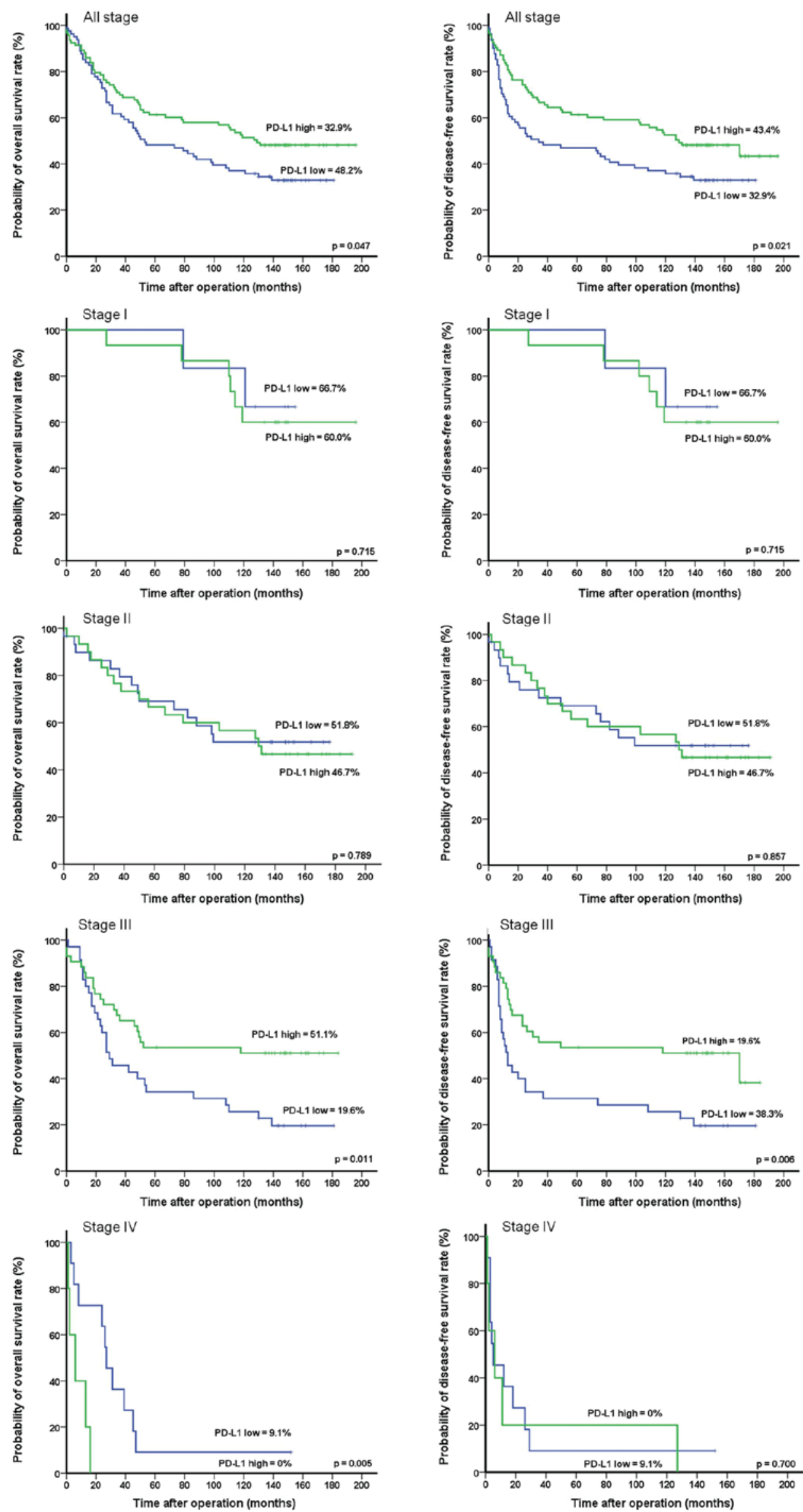

Figure 2. Ten-year overall and disease-free survival of patients with CRC according to PD-L1 expression. The 10-year OS and DFS rates were significantly higher in the high PD-L1 expression group than in the low PD-L1 expression group and low PD-L1 expression was significantly associated with tumor relapse and poor prognosis in stage III CRC. CRC, colorectal cancer. 
Table II. Recurrence patterns according to programmed death-ligand 1 expression.

\begin{tabular}{|c|c|c|c|}
\hline Variables & Low expression $(\mathrm{N}=82)$ & High expression $(\mathrm{N}=93)$ & P-value \\
\hline No. of involved organs & & & 0.418 \\
\hline 1 & $35(42.7)$ & $15(16.1)$ & \\
\hline 2 & $4(4.9)$ & $4(4.3)$ & \\
\hline 3 & $1(1.2)$ & $0(0)$ & \\
\hline Recurrence pattern & & & 0.030 \\
\hline Local recurrence & $5(6.1)$ & $7(7.5)$ & \\
\hline Anastomotic site & $1(1.2)$ & $2(2.2)$ & 0.636 \\
\hline Perirectum & $5(6.1)$ & $6(6.5)$ & 0.923 \\
\hline Pelvic cavity & $3(3.7)$ & $1(1.1)$ & 0.254 \\
\hline Systemic recurrence & $35(42.7)$ & $12(12.9)$ & \\
\hline Liver & $21(25.6)$ & $7(7.5)$ & 0.001 \\
\hline Lung & $5(6.1)$ & $3(3.2)$ & 0.364 \\
\hline Peritoneum & $3(3.7)$ & $2(2.2)$ & 0.550 \\
\hline Extraregional lymph node ${ }^{a}$ & $3(3.7)$ & $2(2.2)$ & 0.550 \\
\hline Abdominal wall & $1(1.2)$ & $0(0)$ & 0.286 \\
\hline Adrenal gland & $1(1.2)$ & $0(0)$ & 0.286 \\
\hline Ureter & $1(1.2)$ & $0(0)$ & 0.286 \\
\hline Ovary & $1(1.2)$ & $0(0)$ & 0.286 \\
\hline Supraclavicular lymph node & $1(1.2)$ & $0(0)$ & 0.286 \\
\hline
\end{tabular}

${ }^{a}$ The extraregional lymph node includes the para-aortic and lateral pelvic lymph node.

and relapse events were 102 and 57, respectively. The 10-year OS and DFS rates were significantly higher in the high PD-L1 expression group than in the low PD-L1 expression group (OS: 48.2 vs. $32.9 \%, \mathrm{P}=0.047$; DFS: 43.3 vs. $32.9 \%, \mathrm{P}=0.021$ ) (Fig. 2). According to the TNM stage subgroups, the OS rates in the low and high PD-L1 expression groups, respectively, were 66.7 and $60.0 \%$ in stage $\mathrm{I}(\mathrm{P}=0.715), 51.8$ and $46.7 \%$ in stage II $(\mathrm{P}=0.789), 19.6$ and $51.1 \%$ in stage III $(\mathrm{P}=0.011)$, and 9.1 and $0 \%$ in stage IV $(\mathrm{P}=0.005)$. The DFS rates in the low and high PD-L1 expression groups, respectively, were 66.7 and $60.0 \%$ in stage $\mathrm{I}(\mathrm{P}=0.715), 51.8$ and $46.7 \%$ in stage II $(\mathrm{P}=0.857), 19.6$ and $38.3 \%$ stage III $(\mathrm{P}=0.006)$, and 9.1 and $0 \%$ in stage IV $(\mathrm{P}=0.700)$. The numbers of involved organs in recurrence did not differ between groups $(\mathrm{P}=0.418$; Table II). The local recurrence rate was $6.1 \%$ in the low PD-L1 expression group and $7.5 \%$ in the high PD-L1 expression group. The sites of local recurrence in the low and high PD-L1 expression groups included the anastomotic site (1.2 vs. $2.2 \%, \mathrm{P}=0.636)$, perirectum (6.1 vs. $6.5 \%, \mathrm{P}=0.923)$, and pelvic cavity ( 3.7 vs. $1.1 \%, \mathrm{P}=0.254)$. The systemic recurrence rate was significantly higher in the low PD-L1 expression group than in the high PD-L1 expression group (42.7 vs. $12.9 \%$, respectively, $\mathrm{P}=0.030$ ). The sites of systemic recurrence most commonly affected in the low and high PD-L1 expression groups included the liver ( 25.6 vs. $7.5 \%, \mathrm{P}=0.001)$, followed by the lungs (6.1 vs. $3.2 \%, \mathrm{P}=0.364)$, peritoneum (3.7 vs., $2.2 \%, \mathrm{P}=0.550)$, extraregional lymph nodes (3.7 vs. $2.2 \%, \mathrm{P}=0.550)$, abdominal wall (1.2 vs. $0 \%, \mathrm{P}=0.286)$, adrenal glands (1.2 vs. $0 \%, \mathrm{P}=0.286)$, ureters $(1.2$ vs. $0 \%, \mathrm{P}=0.286)$, ovaries $(1.2$ vs. $0 \%, \mathrm{P}=0.286)$, and supraclavicular lymph nodes (1.2 vs. $0 \%, \mathrm{P}=0.286)$.
Univariate and multivariate survival analyses of prognostic factors. Univariate analyses revealed that $\mathrm{T}$-stage $(\mathrm{P}=0.005$ and $\mathrm{P}=0.004$, respectively), $\mathrm{N}$-stage $(\mathrm{P}=0.001$ and $\mathrm{P}<0.001$, respectively), tumor differentiation $(\mathrm{P}=0.011$ and $\mathrm{P}=0.014$, respectively), lymphovascular invasion $(\mathrm{P}=0.005$ and $\mathrm{P}=0.006$, respectively), $\mathrm{PD}-\mathrm{L} 1$ expression $(\mathrm{P}=0.047$ and $\mathrm{P}=0.021$, respectively), and perinodal extension $(\mathrm{P}<0.001$ and $\mathrm{P}<0.001$, respectively) were significantly associated with OS and DFS (Table III) (Fig. 3). Multivariate analysis found that T-stage [hazard ratio (HR), 1.888; $95 \%$ confidence interval [CI], 1.022-3.488, $\mathrm{P}=0.042$ ] and perinodal extension (HR, 2.927; 95\% CI, 1.693-5.060, $\mathrm{P}<0.001)$ were independent prognostic factors for OS and PD-L1 expression (HR, 1.586; 95\% CI, 1.069-2.353, $\mathrm{P}=0.022)$, while T-stage ( HR, 1.903; 95\% CI, 1.033-3.508, $\mathrm{P}=0.039)$ and perinodal extension (HR, 3.057; $95 \% \mathrm{CI}, 1.776-5.259, \mathrm{P}<0.001)$ were independent prognostic factors for DFS (Table IV).

\section{Discussion}

PD-L1 expression has been reported in tumor cells or tumor-infiltrating immune cells in several malignancies, including $\mathrm{CRC}$, and may play a central role in immune-oncologic interactions $(19,28,29)$. The present study examined the effects of PD-L1 expression on long-term oncologic outcomes and recurrence patterns among patients with CRC. We found that PD-L1 expression was significantly associated with tumor recurrence and poor prognosis and was an independent prognostic factor for DFS, especially in stage III $\mathrm{CRC}$. Moreover, the systemic recurrence rate was significantly 

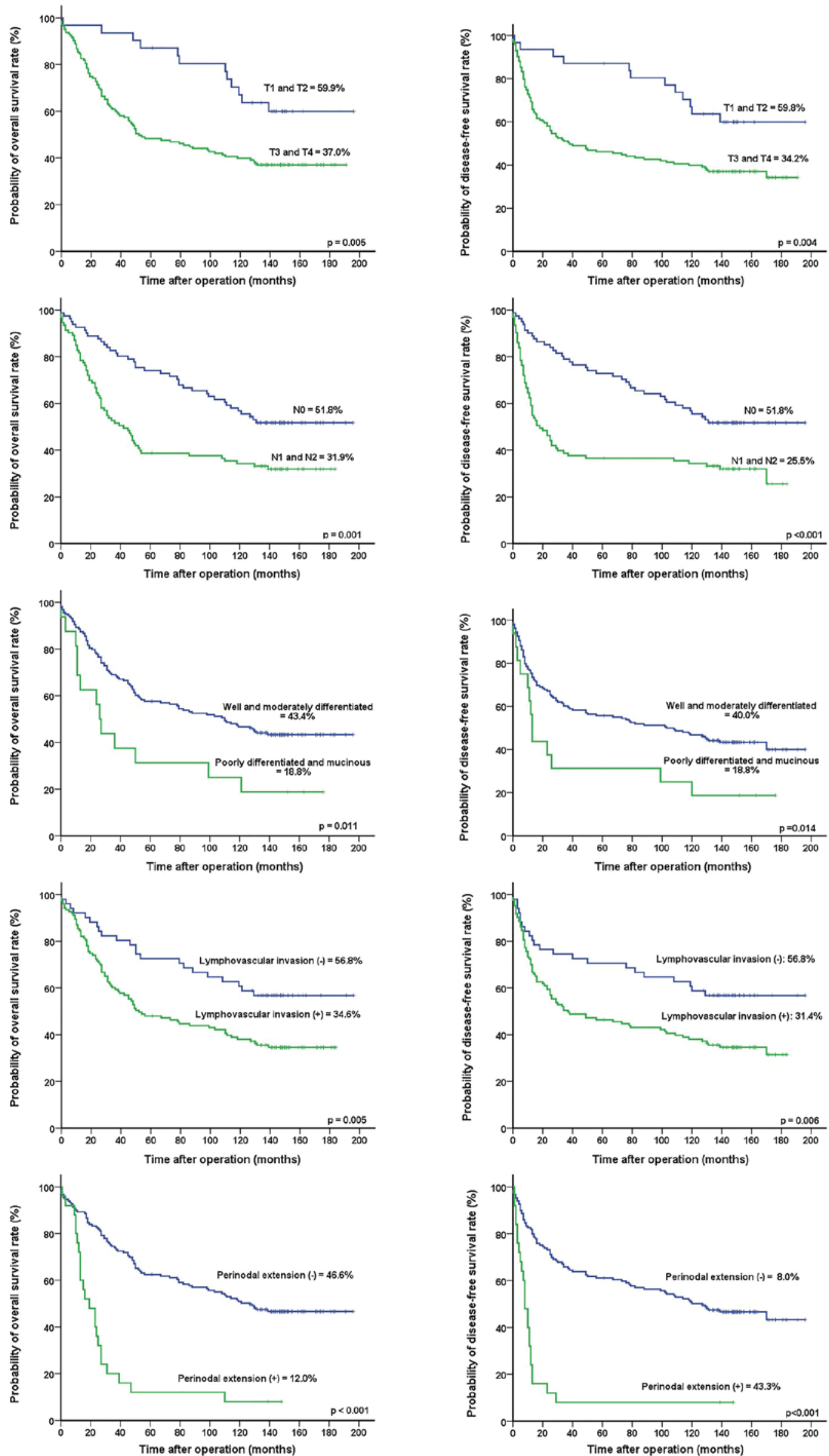

Figure 3. Ten-year overall and disease-free survival of patients with CRC according to prognostic variables with statistical significance. Univariate analyses revealed that T-stage, $\mathrm{N}$-stage, tumor differentiation, lymphovascular invasion, PD-L1 expression, and perinodal extension were significantly associated with overall and disease-free survival. CRC, colorectal cancer. 
Table III. Prognostic factors of survival in univariate analysis.

\begin{tabular}{|c|c|c|c|c|c|}
\hline Prognostic factor & No. $(n=175)$ & OS $(\%)$ & P-value & DFS (\%) & P-value \\
\hline Age (years) & & & 0.554 & & 0.466 \\
\hline$\leq 60$ & 47 & 48.9 & & 48.9 & \\
\hline$>60$ & 128 & 38.0 & & 33.8 & \\
\hline Sex & & & 0.173 & & 0.130 \\
\hline Male & 105 & 37.1 & & 33.1 & \\
\hline Female & 70 & 46.8 & & 46.8 & \\
\hline Location & & & 0.916 & & 0.747 \\
\hline Right-sided & 31 & 41.9 & & 41.9 & \\
\hline Left-sided & 144 & 40.9 & & 37.2 & \\
\hline Tumor stage & & & 0.005 & & 0.004 \\
\hline $\mathrm{T} 1$ and $\mathrm{T} 2$ & 31 & 59.9 & & 59.8 & \\
\hline $\mathrm{T} 3$ and $\mathrm{T} 4$ & 144 & 37.0 & & 34.2 & \\
\hline Nodal stage & & & 0.001 & & $<0.001$ \\
\hline No & 82 & 51.8 & & 51.8 & \\
\hline $\mathrm{N} 1$ and $\mathrm{N} 2$ & 93 & 31.9 & & 25.5 & \\
\hline Histology & & & 0.011 & & 0.014 \\
\hline Well and moderately differentiated & 159 & 43.4 & & 40.0 & \\
\hline Poorly differentiated and mucinous & 16 & 18.8 & & 18.8 & \\
\hline Lymphovascular invasion & & & 0.005 & & 0.006 \\
\hline No & 51 & 56.8 & & 56.8 & \\
\hline Yes & 124 & 34.6 & & 31.4 & \\
\hline PD-L1 expression & & & 0.047 & & 0.021 \\
\hline Low & 82 & 32.9 & & 32.9 & \\
\hline High & 93 & 48.2 & & 43.3 & \\
\hline Perinodal extension & & & $<0.001$ & & $<0.001$ \\
\hline No & 150 & 46.6 & & 43.3 & \\
\hline Yes & 25 & 12 & & 8 & \\
\hline
\end{tabular}

DFS, disease-free survival; OS, overall survival; PALN, para-aortic lymph node; PreOP CEA, preoperative carcinoembryonic antigen; PD-L1, programmed death-ligand 1.

higher and hepatic recurrence was more common in the low group than in the high expression group.

Previous studies have reported conflicting results as to whether PD-L1 expression indicates a better or worse prognosis in CRC, possibly due to differences in study populations and designs $(21,23,30)$. In the present study, the prognostic impact of PD-L1 expression on long-term oncologic outcomes in CRC differed according to the TNM stage. In early stages, including stages I and II, there was no significant between-group difference; however, the long-term oncologic outcomes of patients with stage III disease was significantly better in the high PD-L1 expression group. In this context, our results underscore the specificities of tumor immune system interactions and microenvironments in CRC according to disease stage.

Our evaluation of the recurrence patterns according to the PD-L1 expression status revealed a significantly higher systemic recurrence rate in the low PD-L1 expression group than that in the high PD-L1 expression group. Moreover, low PD-L1 expression was significantly associated with hepatic recurrence. The high systemic recurrence rate and significant association with hepatic recurrence in the low PD-L1 expression group may be reflected in the poor prognosis.

CRC with MMR defects shows high microsatellite instability (MSI) and accounts for 12 to $15 \%$ of colorectal carcinomas. These tumors are infiltrated by higher numbers of lymphocytes and are characterized by a more favorable prognosis compared to those in MMR-proficient tumors. Some studies have reported different impacts of PD-L1 expression on survival according to microsatellite status. Dunne et al (26) demonstrated that PD-L1 expression was associated with a significantly worse recurrence-free survival in mismatch-repair-deficient tumors, whereas PD-L1 expression did not show a statistically significant association with recurrence-free survival in mismatch-repair-proficient tumors. In contrast, Droeser et al (23) reported that high PD-L1 expression in mismatch-repair-proficient CRC was associated with early tumor stage, absence of lymph node metastases, lower tumor grade, absence of vascular invasion, high numbers of tumor-infiltrating CD8+ T cells, and 
Table IV. Prognostic factors of survival in multivariate analysis.

\begin{tabular}{|c|c|c|c|c|}
\hline \multirow[b]{2}{*}{ Prognostic factor } & \multicolumn{2}{|c|}{ Overall survival } & \multicolumn{2}{|c|}{ Disease-free survival } \\
\hline & $\mathrm{HR}(95 \% \mathrm{CI})$ & P-value & $\mathrm{HR}(95 \% \mathrm{CI})$ & P-value \\
\hline \multicolumn{5}{|l|}{ Tumor stage } \\
\hline $\mathrm{T} 3$ and $\mathrm{T} 4 \mathrm{vs} . \mathrm{T} 1$ and $\mathrm{T} 2$ & $1.888(1.022-3.488)$ & 0.042 & $1.903(1.033-3.508)$ & 0.039 \\
\hline \multicolumn{5}{|l|}{ Histology } \\
\hline $\begin{array}{l}\text { Poorly differentiated and mucinous vs. } \\
\text { well and moderately differentiated }\end{array}$ & $1.647(0.906-2.995)$ & 0.102 & $1.409(0.768-2.586)$ & 0.268 \\
\hline Lymphovascular invasion & $1.615(0.992-2.629)$ & 0.054 & $1.593(0.980-2.591)$ & 0.061 \\
\hline \multicolumn{5}{|l|}{ Programmed death-ligand 1 expression } \\
\hline Low vs. high & $1.274(0.852-1.904)$ & 0.238 & $1.586(1.069-2.353)$ & 0.022 \\
\hline \multicolumn{5}{|l|}{ Nodal stage } \\
\hline Positive vs. $\leq$ negative & $1.306(0.829-2.056)$ & 0.249 & $1.430(0.912-2.243)$ & 0.119 \\
\hline \multicolumn{5}{|l|}{ Perinodal extension } \\
\hline Positive vs. $\leq$ negative & $2.927(1.693-5.060)$ & $<0.001$ & $3.057(1.776-5.259)$ & $<0.001$ \\
\hline
\end{tabular}

HR, hazard ratio; CI, confidence interval.

an improved 5-year survival rate. Unfortunately, we did not evaluate the status of germline mutations in $M L H 1, M S H 2$, MSH6, and PMS2; thus, further studies are needed to assess the possible association between MSI status and PD-L1 expression in tumor cells.

Adjuvant chemotherapy has an established role in patients with stage III and high-risk stage II CRC; however, its use remains controversial in stage II disease due to its restriction to a small subgroup of patients with high-risk prognostic factors. Dunne et al (26) used relapse follow-up data to find that patients with high PD-L1 expression had a significantly better outcome than that in patients with low expression in the untreated stage III population; however, the correlation between survival and high PD-L1 expression was lost in the stage III patients treated with adjuvant chemotherapy. They suggested that patients with high PD-L1 expression should not be administered 5-FU-based adjuvant chemotherapy following surgery. However, neither high nor low PD-L1 expression showed a statistically significant association with recurrence-free survival in our study, regardless of adjuvant chemotherapy (data not shown).

Our study has several limitations, including the small number of patients, its retrospective nature, and the lack of investigation of other immune-oncologic biomarkers such as MSI status, K-ras and BRAF mutations, and the expression of other immune checkpoints in tumor and immune cells. Further studies are needed to determine the possible association of MSI status with immune checkpoint molecules in tumor and immune cells in different stages or statuses.

Analysis of our long-term data indicates that love PD-L1 expression is significantly associated with tumor relapse and poor prognosis in CRC.

\section{Acknowledgements}

Not applicable.

\section{Funding}

The present study was supported by the Keimyung University Research Grant of 2017 (grant no. 20170567).

\section{Availability of data and materials}

All data generated or analyzed during the present study are included in this published article.

\section{Authors' contributions}

SUB and ISH conceived and designed the study and collected and assembled the data. SUB, ISH and SKB provided administrative support. SKB and ISH provided the study materials and enrolled the patients. SUB, ISH, SKB and NKK performed the data analysis and interpretation. All authors wrote the manuscript and final approved the version to be published.

\section{Ethics approval and consent to participate}

The present study was approved by the Institutional Review Board of Keimyung University and Donsan Medical Center (IRB No. 2017-11-037) and performed in accordance with the principles of the Declaration of Helsinki. All patients provided written informed consent to allow the use of their tissues.

\section{Patient consent for publication}

Not applicable.

\section{Competing interests}

The authors declare that they have no competing interests. 


\section{References}

1. Shin A, Kim KZ, Jung KW, Park S, Won YJ, Kim J, Kim DY and $\mathrm{Oh} \mathrm{JH}$ : Increasing trend of colorectal cancer incidence in Korea, 1999-2009. Cancer Res Treat 44: 219-226, 2012

2. Arnold M, Sierra MS, Laversanne M, Soerjomataram I, Jemal A and Bray F: Global patterns and trends in colorectal cancer incidence and mortality. Gut 66: 683-691, 2017.

3. Colussi D, Brandi G, Bazzoli F and Ricciardiello L: Molecular pathways involved in colorectal cancer: Implications for disease behavior and prevention. Int J Mol Sci 14: 16365-16385, 2013

4. Di Caro G, Marchesi F, Laghi L and Grizzi F: Immune cells: Plastic players along colorectal cancer progression. J Cell Mol Med 17: 1088-1095, 2013.

5. Ogino S, Galon J, Fuchs CS and Dranoff G: Cancer immunology-analysis of host and tumor factors for personalized medicine. Nat Rev Clin Oncol 8: 711-719, 2011.

6. Zaanan A, Fléjou JF, Emile JF, Des GG, Cuilliere-Dartigues P, Malka D, Lecaille C, Validire P,Louvet C, Rougier P, et al: Defective mismatch repair status as a prognostic biomarker of disease-free survival in stage III colon cancer patients treated with adjuvant FOLFOX chemotherapy. Clin Cancer Res 17: 7470-7478, 2011.

7. Sinicrope FA, Shi Q, Smyrk TC, Thibodeau SN, Dienstmann R, Guinney J, Bot BM, Tejpar S, Delorenzi M, Goldberg RM, et al: Molecular markers identify subtypes of stage III colon cancer associated with patient outcomes. Gastroenterology 148: 88-99, 2015.

8. Galon J, Mlecnik B, Bindea G, Angell HK, Berger A, Lagorce C, Lugli A, Zlobec I, Hartmann A, Bifulco C, et al: Towards the introduction of the 'Immunoscore' in the classification of malignant tumours. J Pathol 232: 199-209, 2014.

9. Mlecnik B, Bindea G, Angell HK, Maby P, Angelova M, Tougeron D, Church SE, Lafontaine L, Fischer M, Fredriksen T, et al: Integrative analyses of colorectal cancer show immunoscore is a stronger predictor of patient survival than microsatellite instability. Immunity 44: 698-711, 2016.

10. Topalian SL, Drake CG and Pardoll DM: Immune checkpoint blockade: A common denominator approach to cancer therapy. Cancer Cell 27: 450-461, 2015.

11. Ostrand-Rosenberg S, Horn LA and Haile ST: The programmed death-1 immune-suppressive pathway: Barrier to antitumor immunity. J Immunol 193: 3835-3841, 2014.

12. Rooney MS, Shukla SA, Wu CJ, Getz G and Hacohen N: Molecular and genetic properties of tumors associated with local immune cytolytic activity. Cell 160: 48-61, 2015.

13. Hirano F, Kaneko K, Tamura H, Dong H, Wang S, Ichikawa M, Rietz C, Flies DB, Lau JS, Zhu G, et al: Blockade of B7-H1 and PD-1 by monoclonal antibodies potentiates cancer therapeutic immunity. Cancer Res 65: 1089-1096, 2005.

14. Konishi J, Yamazaki K, Azuma M, Kinoshita I, Dosaka-Akita H and Nishimura M: B7-H1 expression on non-small cell lung cancer cells and its relationship with tumor-infiltrating lymphocytes and their PD-1 expression. Clin Cancer Res 10: 5094-5100, 2004

15. Ohigashi Y, Sho M, Yamada Y, Tsurui Y, Hamada K, Ikeda N, Mizuno T, Yoriki R, Kashizuka H, Yane K, et al: Clinical significance of programmed death-1 ligand-1 and programmed death-1 ligand-2 expression in human esophageal cancer. Clin Cancer Res 11: 2947-2953, 2005.

16. Thompson RH, Gillett MD, Cheville JC, Lohse CM, Dong H, Webster WS, Krejci KG, Lobo JR, Sengupta S, Chen L, et al: Costimulatory B7-H1 in renal cell carcinoma patients: Indicator of tumor aggressiveness and potential therapeutic target. Proc Natl Acad Sci USA 101: 17174-17179, 2004.

17. Hamanishi J, Mandai M, Iwasaki M, Okazaki T, Tanaka Y, Yamaguchi K, Higuchi T, Yagi H, Takakura K, Minato N, et al: Programmed cell death 1 ligand 1 and tumor-infiltrating CD8+ T lymphocytes are prognostic factors of human ovarian cancer. Proc Natl Acad Sci USA 104: 3360-3365, 2007.
18. Le DT, Durham JN, Smith KN, Wang H, Bartlett BR, Aulakh LK, Lu S, Kemberling H, Wilt C, Luber BS, et al: Mismatch repair deficiency predicts response of solid tumors to PD-1 blockade. Science 357: 409-413, 2017.

19. Sabatier R, Finetti P, Mamessier E, Adelaide J, Chaffanet M, Ali HR, Viens P, Caldas C, Birnbaum D and Bertucci F: Prognostic and predictive value of PDL1 expression in breast cancer. Oncotarget 6: 5449-5464, 2015.

20. Hino R, Kabashima K, Kato Y, Yagi H, Nakamura M, Honjo T, Okazaki T and Tokura Y: Tumor cell expression of programmed cell death-1 ligand 1 is a prognostic factor for malignant melanoma. Cancer 116: 1757-1766, 2010.

21. Wu P, Wu D, Li L, Chai Y and Huang J: PD-L1 and survival in solid tumors: A meta-analysis. PLoS One 10: e0131403, 2015.

22. Zhu Z, Jin Z, Zhang M, Tang Y, Yang G, Yuan X, Yao J and Sun D: Prognostic value of programmed death-ligand 1 in sarcoma: A meta-analysis. Oncotarget 8: 59570-59580, 2017.

23. Droeser RA, Hirt C, Viehl CT, Frey DM, Nebiker C, Huber X Zlobec I, Eppenberger-Castori S, Tzankov A, Rosso R, et al: Clinical impact of programmed cell death ligand 1 expression in colorectal cancer. Eur J Cancer 49: 2233-2242, 2013.

24. Lee LH, Cavalcanti MS, Segal NH, Hechtman JF, Weiser MR, Smith JJ, Garcia-Aguilar J, Sadot E, Ntiamoah P, Markowitz AJ, et al: Patterns and prognostic relevance of PD-1 and PD-L1 expression in colorectal carcinoma. Mod Pathol 29: 1433-1442, 2016.

25. Saigusa S, Toiyama Y, Tanaka K, Inoue Y, Mori K, Ide S, Imaoka H, Kawamura M, Mohri $\mathrm{Y}$ and Kusunoki M: Implication of programmed cell death ligand 1 expression in tumor recurrence and prognosis in rectal cancer with neoadjuvant chemoradiotherapy. Int J Clin Oncol 21: 946-952, 2016.

26. Dunne PD, McArt DG, O'Reilly PG, Coleman HG, Allen WL, Loughrey M, Van Schaeybroeck S, McDade S, Salto-Tellez M, Longley DB, et al: Immune-derived PD-L1 gene expression defines a subgroup of stage II/III colorectal cancer patients with favorable prognosis who may be harmed by adjuvant chemotherapy. Cancer Immunol Res 4: 582-591, 2016.

27. Koganemaru S, Inoshita N, Miura Y, Miyama Y, Fukui Y, Ozaki Y, Tomizawa K, Hanaoka Y, Toda S, Suyama K, et al: Prognostic value of programmed death-ligand 1 expression in patients with stage III colorectal cancer. Cancer Sci 108: 853-858, 2017.

28. Shen JK, Cote GM, Choy E, Yang P, Harmon D, Schwab J, Nielsen GP, Chebib I, Ferrone S, Wang X, et al: Programmed cell death ligand 1 expression in osteosarcoma. Cancer Immunol Res 2: 690-698, 2014.

29. Curiel TJ, Wei S, Dong H, Alvarez X, Cheng P, Mottram P, Krzysiek R, Knutson KL, Daniel B, Zimmermann MC, et al: Blockade of B7-H1 improves myeloid dendritic cell-mediated antitumor immunity. Nature Med 9: 562-567, 2003.

30. Song M, Chen D, Lu B, Wang C, Zhang J, Huang L, Wang X, Timmons CL, Hu J, Liu B, et al: PTEN loss increases PD-L1 protein expression and affects the correlation between PD-L1 expression and clinical parameters in colorectal cancer. PLoS One 8: e65821, 2013.

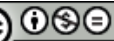

This work is licensed under a Creative Commons Attribution-NonCommercial-NoDerivatives 4.0 International (CC BY-NC-ND 4.0) License. 